\title{
On the origins of calculation abilities
}

\author{
A. Ardila \\ Instituto Colombiano de Neuropsicología, Bogotá, Colombia \\ Correspondence to: A. Ardila, Apartado Aéreo 17021, Bogotá, Colombia, South America
}

\begin{abstract}
A historical review of calculation abilities is presented. Counting, starting with finger sequencing, has been observed in different ancient and contemporary cultures, whereas number representation and arithmetic abilities are found only during the last 5000-6000 years. The rationale for selecting a base of ten in most numerical systems and the clinical association between acalculia and finger agnosia are analyzed. Finger agnosia (as a restricted form of autotopagnosia), right-left discrimination disturbances, semantic aphasia, and acalculia are proposed to comprise a single neuropsychological syndrome associated with left angular gyrus damage. A classification of calculation disturbances resulting from brain damage is presented. It is emphasized that using historical/anthropological analysis, it becomes evident that acalculia, finger agnosia, and disorders in right-left discrimination (as in general, in the use of spatial concepts) must constitute a single clinical syndrome, resulting from the disruption of some common brain activity and the impairment of common cognitive mechanisms.
\end{abstract}

Keywords: Acalculia - Anarithmetia - Calculation abilities - Finger agnosia - Gerstmann syndrome - Semantic aphasia

\section{INTRODUCTION}

Our understanding of brain organization of calculation abilities has notably improved during the last few years (see Grafman et al., 1982, 1989; Warrington, 1982; Boller and Grafman, 1985; Levin and Spiers, 1985; McCloskey et al., 1986; McCloskey and Carmazza, 1987; Grafman, 1988). Different classifications of calculation disturbances have been proposed (e.g. Hécaen et al., 1961; Grafman et al., 1982; Grafman, 1988; Ardila and Rosselli, 1990). It seems reasonable to propose the existence of primary calculation defects, associated with left posterior parietal damage (Hécaen et al., 1961; Grafman et al., 1982; Ardila and Rosselli, 1990), and secondary calculation impairments, resulting from linguistic, spatial, attentional, memory, or other associated cognitive deficits. Primary acalculia (anarithmetia) is usually found correlated with finger agnosia, right-left discrimination impairments, and general difficulties in using spatial concepts in language (Ardila et al., 1989a).

Using our current knowledge of neuropsychology, it would seem reasonable to suppose that calculation abilities, right-left discrimination, and finger gnosis might have a common historical origin. In the case of brain damage, they are usually impaired in a parallel way, pointing to some common underlying brain activity and similar cognitive mechanisms.

Arithmetic abilities represent a relatively recent human acquisition. Furthermore, during the last decades calculation abilities have evolved rapidly with the increasingly complex disciplines of calculus, geometry, physics, and mathematical logic. Further, the recent introduction of computers and pocket calculators has radically changed contemporary human's habits in performing calculations.

\section{DEVELOPMENT OF CALCULATION ABILITIES}

Different levels of numerical knowledge have been distinguished (Klein and Starkey, 1987). Global quantification or numerosity perception defines the discrimination between collections containing different numbers of objects (Davis et al., 1985). However, global quantification does not represent a truly numerical process, because it does not suppose a one-to-one correspondence. Enumeration represents the most elementary type of numerical knowledge (Klein and Starkey, 1987). Correspondence construction constitutes a type of enumeration used to represent the number of objects in a collection and to compare collections. It implies, in consequence, a one-to-one correspondence. Counting represents a sophisticated form of enumeration: a unique number name is paired with each object in a collection, and the final number name that is used stands for the cardinal value of that collection. Arithmetics represents an 
advanced numerical system, that comprises number permutability (e.g. adding, subtracting).

Chimpanzees are capable of various forms of numerical competence, including some correspondence constructions for low quantities (Premack, 1976; Davis and Pérusse, 1988). Most likely, Homo sapiens' ancestors may have been capable of using correspondence constructions in some social activities, such as food sharing. It has been proposed that Homo habilis (ancestor of Homo erectus, living about 2.5 million years ago) used correspondence constructions when butchering large animal carcasses (Parker and Gibson, 1979). Distributing pieces of a divided whole (e.g. a prey) into equal parts required the ability to construct one-to-one correspondences. Probably, paleolithic man was able to match the number of objects in different groups, and eventually, the number of objects in a collection with the number of items in some external cue system, e.g. fingers or pebbles (incidentally, calculus means pebbles).

Human infants are able to recognize numerosity for small quantities (usually up to three-six items) (Antell and Keating, 1983), but the ability to construct correspondences emerges only during the child's second year (Langer, 1986). During the second year the child also begins to use some number names, and usually develops the ability to correctly count up to three. The child thus acquires the knowledge of two basic principles in counting: the one-toone principle (each object in a collection is to be paired with one and only one number name), and the stable order principle (each name is assigned to a permanent ordinal position in the list), but they do not exhibit yet a cardinal principle (the final number name used in a counting sequence refers to the cardinal value of the sequence) (Klein and Starkey, 1987). The cardinal principle is observed in 3-year-old children (Gelman and Meck, 1983). Computational strategies (e.g. adding: if a new item is included in a collection, the collection will become larger and the next cardinal number name will be given to that collection) are found in 3- to 5-year-old children (Groen and Resnick, 1977), initially only for small quantities. Adding and subtracting numerical quantities and the use of computational principles is observed in first-second grade children, but they only become able to manipulate the principles of multiplying and dividing after a long and painstaking training period, during third-fifth school grade.

\section{CALCULATION AND FINGER GNOSIS}

Historically, calculation abilities seem to develop from counting, which, as in child development (Hitch et al., 1987), begins with the sequencing of the fingers (correspondence construction). The fingers [and toes; as a matter of fact, many languages, e.g. Spanish, use a single word (dedo) to name fingers and toes] are usually sequenced in a particular order, and this represents a basic procedure found in different, both ancient and contemporary, cultures around the world (Cauty, 1984; Levy-Bruhl, 1910, 1947). Taking a typical example as an illustration, according to Queixalos (1989) the Colombian Sikuani Indians count in the following way: the person (a child when learning to count or an adult when counting) places his or her left hand in supination; to point number 1, the right index points to the left little finger, which is then bent. The order followed in counting is always from the little finger to the index. To point to number 5 , the hand is turned and the fingers opened; for 6, both thumbs are joined, the left fingers are closed, and the right opened; they are opened one after the other for 7, 8, 9 and 10. Between 11 and 20, the head points to the feet and the sequence is reinitiated. The lexicon used is:

1: kae (the unit, one).

2: aniha-behe (a pair, both).

3: akueyabi.

4: penayanatsi (accompanied; that is, the fingers together).

5: kae-kabe (one hand).

Numbers from 6 to 9 are formed with "one hand and (a certain number) of fingers". Ten becomes "two hands".

6: kae-kabe kae-kabesito-nua (one hand and one finger).

7: kae-kabe aniha-kabesito-behe (one hand and a pair of fingers).

10: aniha-kabe-behe (two hands).

"Two hands" is maintained between 10 and 20. Toes (taxawusito) are added between 11 and 14 and "one foot" (kaetaxu) is used in 15 . Twenty is "two hands together with two feet"

11: aniha-kabe-behe kae-taxuwusito (two hands and one toe).

12: aniha-kabe-behe aniha-taxuwusito-behe (two hands and two toes).

15: aniha-kabe-behe kae-taxu-behe (two hands and one foot).

16: aniha-kae-behe kae-taxu-behe kae-taxuwusito (two hands, one foot and one toe).

20: aniha-kabe-behe aniha-taxu-behe (two hands and two feet).

Fingers are named according to their order in counting (as mentioned above, counting begins always with the little finger of the left hand). Sikuani language possesses number words only up to three (kae, aniha-behe, akueyabi). Four (penayanatsi = accompanied, together) represents a correspondence construction. Strictly speaking, Sikuani language counts only up to 3 . From 4 to 20 , they use a correspondence construction, not really counting; and for higher quantities, they use a global quantification.

In Amerindian languages, for higher than 10 or 20 
figures, "many" is most often used (global quantification principle) (Cauty, 1984); or, they can refer to other people's hands (correspondence construction) (e.g. 35 might be something like "my two hands, my two feet, my father's two hands, my father's one foot"). "Twenty" sometimes become something like "one person", a sort of higher order numeral. It is interesting to note that in some contemporary languages (such as English and Spanish) "one" means the unit, but it is also used as a sort of indefinitive personal pronoun. Twenty is the base number in the Maya's numerical system (Swadesh, 1967; Cauty, 1984). In many contemporary languages, a 10 and/or 20 base is evident. The strong relationship existing between numerical knowledge, finger gnosis, and lateral knowledge is evident. Finger agnosia (and even right-left discrimination disturbances) could be interpreted as a restricted form of autotopagnosia (Ardila et al., 1989a).

Consequently, it is not surprising to find that a decimal system has been most often developed. Simultaneously or very close in time, decimal systems appeared in different countries (Sumer, Egypt, India, and Crete). Different symbols were used to represent $1,10,100$, and 1000 (Childe, 1936). However, there is an interesting and intriguing exception: Sumerians and later Babylonians (about $2000 \mathrm{BC}$ ) developed not only a decimal but also a sexagesimal system: a symbol represented 60 or any $60-$ multiple; and other different symbols represented the number 10 and any 10-multiple. Thus, for example, the number 173 was represented: $2 \times 60$ (the symbol for 60 repeated twice) $+5 \times 10$ (the symbol for 10 repeated five times) +3 (a symbol for units repeated three times). A base of 60 has remained for some contemporary time measures (e.g. hours, minutes). Twelve is also frequently maintained as a "second-order" unit (e.g. a dozen). Evidently 60 results from "five times twelve". Five obviously is "one hand", and the question becomes where does 12 come from? What are the two additional units? It might be the 10 fingers plus the two feet (individuality of components is easier to appreciate in the hands than in the feet), but this is only speculation, although feasible according to our knowledge about counting procedures used in different cultural groups (Levy-Bruhl, 1910, 1947). It is interesting to note that the Maya Indians developed a similar system, but having 20 as a base (León-Portilla, 1986); they used different symbols to represent $20,400(20 \times 20)$, and $8000(20 \times 20 \times 20)$ (Cauty, 1984).

Writing numbers appeared earlier in history than writing language. Some cultures (e.g. Incas) developed a number-representing system, but not a language-representing system (Swadesh, 1967). In Sumer, the first number writing system has been found (about 3000 BC) (Childe, 1936). In Egypt, India and later in Crete, a similar system was developed: units were represented by a conventional symbol (usually a stroke) repeated several times to mean a digit between one and nine; a different symbol was used for 10 and 10-multiples. Positional digit value is clearly disclosed in Babylonians, and about $1000 \mathrm{BC}$ the zero was introduced. Positional value and zero are also disclosed in Maya Indians (León-Portilla, 1986). Fractions were commonly used by Egyptians and Babylonians.

Adding, subtracting, multiplying and dividing were possible in the Egyptian system, but following procedures quite different to those we currently use. They based multiplication and division on the "duplication" and "halving" method (Childe, 1936). So, to multiply $12 \times 18$, the following procedure was followed:

$\begin{array}{rr}1 & 18 \\ 2 & 36 \\ { }^{*} 4 & 72 \\ { }^{*} 8 & \underline{144} \\ \text { Total } & 216\end{array}$

(The number 18 is duplicated one or several times, and the amounts corresponding to $12(4+8$ in this example) are selected and summed up: $72+144=216$.) For dividing, the inverse procedure was used. So, to divide 19 by 8 would be:

$\begin{array}{rr}1 & 8 \\ { }^{*} 2 & 16 \\ 2 & 4 \\ { }^{*} 4 & 2 \\ { }^{*} 8 & 1\end{array}$

That is, $2+4+8(2+1 / 4+1 / 8$, that is 2.375$)$.

"Digit" (from digitus, Latin) in English or Spanish (dígito) means number but also finger. Latin number notation was originally Etruscan (Turner, 1984), and referred (as everywhere) to the fingers. Five (V) represented the arm bent (that is, all the fingers of the hand), and $10(\mathrm{X})$ the two arms crossed.

Measure units were also developed starting with the body dimensions (fingers, hands, arm, steps, etc.). This tendency to use the human body as a measure unit is currently reflected in some contemporary measure units (e.g. foot).

In neuropsychology, some common brain activity for finger knowledge and calculation abilities can be assumed. Finger agnosia and acalculia appear as two (out of four) signs of a single clinical syndrome (Gerstmann, 1940), usually known as "Gerstmann syndrome". For prehistorical man, finger agnosia and acalculia could have represented the same defect.

In brief, arithmetical abilities and number representation have a history of only some 5000-6000 years. Most likely, during the Stone Age only simple counting (and of course, "bigger" and "smaller" concepts) was present, represented by the sequencing of the fingers (correspondence construction). Finger knowledge and counting depended to a certain extent upon the same cognitive 
ability. Perhaps within the next century, calculation abilities (as currently understood) might be replaced by the use of computers.

\section{CULTURAL AND EDUCATIONAL VARIABLES IN CALCULATION ABILITIES}

Some studies have been devoted to the analysis of calculation abilities in different cultural contexts and in people with different educational backgrounds (e.g. Levy-Bruhl, 1910, 1947; Cauty, 1984; Grafman and Boller, 1987). Rosin (1973) analyzed the way illiterates perform arithmetical tasks. It was observed that calculation was laborious and strongly relied on memorizing each step. For counting, fingers were used, with large numbers requiring representing the hands. Often, doubling and halving the figures was used for arithmetical operations (as observed in the Egyptian division and multiplication systems). For actual trading and marketing, the operations could be initially performed visually using physical entities, and the results retained in memory.

Posner (1982) analyzed the development of mathematical concepts in West African children aged 5-10. A mild effect of experimental factors on the ability to judge the magnitude of numerical quantities was observed; counting was noted in all children, usually relying on size cues for small quantities.

Casual observation of illiterates reveals that they can use simple numerical concepts and they easily handle money in daily activities (at least in a country such as Colombia where bills of different value have different color, although not different sizes). Illiterates readily recognize the "bigger" and "smaller" bills, and can perform simple computations (e.g. a 500 peso bill is equivalent to two 200 peso bills plus one 100 peso bill). However, to perform subtractions is particularly painstaking, and illiterates easily get confused (e.g. when shopping). They usually cannot multiply or divide, except by 10 (e.g. 3, 30, 300, etc.), and two, doubling and halving figures (e.g. 200,100, 50, etc). This ability to multiply and divide by 10 and 2 is used to perform simple arithmetic calculations. Illiterates also use a significant amount of everyday numerical facts: dates (e.g. "today is 12 August 1992"), time (e.g. "I work eight hours a day: from 8 a.m. to 4 p.m."; "I am 45 years old"), weight (e.g. "the cow weighs 350 kilograms"), distance measures (e.g. "from my house to the park there are five blocks"), etc. Illiterates can also use simple fractions (e.g. half, quarter, tenth). In brief, illiterates can develop some calculation abilities (i.e. counting, magnitude estimation, simple adding and subtracting). More complex arithmetical skills evidently depend on schooling.

Grafman and Boller (1987) proposed that some arithmetic skills appear to be genetically linked (e.g. equival- ence or certain counting skills), and some are educationally linked (e.g. arithmetic calculation and the "tool" used to calculate: fingers, abacus, calculator, computer, or the brain). It is reasonable to expect that some common basic numerical strategies will be found in different cultural groups.

\section{RIGHT-LEFT DISCRIMINATION}

All known languages have different words to refer to right and left; all of them also have other spatial relationship words, such as up and down (Greenberg, 1978; Hagége, 1982). Defects in understanding and using these words are observed in cases of left angular gyrus damage, associated with the language disturbance known as "semantic aphasia" (Luria, 1966, 1973; Hier et al., 1980; Ardila et al., 1989a); and in the neuropsychological syndrome known as "Gerstmann syndrome" (Strub and Geschwind 1983; Kolb and Whishaw, 1990; Mazzoni et al., 1990; Ardila and Rosselli, 1992).

"Up-down" is sometimes used to refer to east-west (or to any other horizontal relationship), becoming not only a vertical but also a horizontal spatial reference. However, it is not always evident what the criterion or reference point is accompanying the use of the words: it may be the sun, it may be the closest river, or it may be a specific place (for example, a hill) (Queixalos, 1985). This tendency to use "up-down" in a horizontal dimension, is still evident in contemporary languages. In Bogotá everybody will tell you that, to go from the airport to downtown you have to go up the Eldorado Avenue; visitors will have some difficulty understanding why up, since Bogotá is virtually a flat city. By the same token, it may be difficult for a foreigner to understand why the commercial and administrative center in a city is named in English as "downtown". In the first case, it is up because street numbering decreases. In the second case (to the best of my knowledge) it is because initially towns were built close to rivers.

Spatial concepts will be strongly reflected in different aspects of language (e.g. in some adverbs and in prepositions) (Luria, 1976). In contemporary languages the underlying spatial content of prepositions is still evident (e.g. to, from, for), and these spatial concepts mediated through language may be disrupted in cases of brain damage associated with the language disorder referred to as semantic aphasia (Luria, 1966, 1976; Hier et al., 1980; Ardila et al. 1989a).

It might be supposed that left angular gyrus syndrome in prehistoric man, most likely, was characterized by finger agnosia and inability to use spatial dimensions in language (right-left but also up-down, and other spatial concepts mediated through language); but obviously agraphia (or anarithmetia, according to our current interpretation of acalculia) was not present. Right-left discrimination is 
associated with finger gnosis and counting. As mentioned above as an example, Colombian Sikuani Indians begin counting always with the left hand.

\section{AUTOTOPAGNOSIA AND THE GERSTMANN SYNDROME}

Autotopagnosia was defined by Pick (1908) as the acquired inability to point and name parts of the body. Patients with autotopagnosia present great difficulty in localizing and naming parts of the body, both of their own and also the examiner's body. A blatant discrepancy is usually observed between the ability to point to external objects and body parts (Hécaen and Albert, 1978). According to De Renzi (1982) autotopagnosia can be defined as an acquired inability to point on verbal command to one's own body parts as well as to those of the examiner or of a human picture; or simply, as the acquired inability to localize, name, or orientate correctly different parts of the body (Goodwin, 1989).

This selective loss in orientating and naming body parts can be observed without any other evident aphasic manifestation (Poncet et al., 1971; Ogden, 1985). Brain-damaged patients with autotopagnosia can show that they understand the names of the parts of the body. They also correctly interpret the performance of another person in body pointing tasks (De Renzi and Scotti, 1970). According to De Renzi (1982), these patients seem to know "what" the parts of the body are, but they fail in finding "where they are". Very often autotopagnosic patients present approximative responses (e.g. when asked to point to the nose, they look for it in the face, not in the arms or the legs, which suggests a "fuzzy" knowledge of the proximity relations and of boundaries between body parts). Sometimes these patients are unable to point to body parts although they can name them when they are pointed at by somebody else (De Renzi and Scotti, 1970; Ogden, 1985).

Several hypotheses have been proposed to explain autotopagnosia: (1) the existence of a language defect restricted to the conceptualization of the parts of the body (Hécaen and Albert, 1978); (2) the presence of an impairment in the spatial reconstruction of the body scheme (De Renzi, 1982; Ogden, 1985); and (3) considering that in some cases the defect includes pointing and naming parts of inanimate objects, De Renzi and Scotti (1970) propose a global deficit in the perceptual integration of elements in a whole. Sirigu et al. (1991) have suggested that multiple levels of representation (sensorimotor, visuospatial, and semantic) are involved in the body knowledge. Semanticlexical and spatial body parts knowledge can become dissociated: although usually patients cannot name body parts but they can localize them (e.g. Ogden, 1985; Semenza, 1988), occasionally the reverse pattern is observed (e.g. Dennis, 1976).
Autotopagnosia is usually correlated with left hemisphere lesions, particularly posterior parietal lobe damage (De Renzi, 1982), but it can be observed also in cases of extended bihemispheric lesions (Hécaen and Albert, 1978). In dementia syndromes, autotopagnosia is frequently observed (Ardila and Rosselli, 1986; Sirigu et al., 1991). Autotopagnosia is usually associated with other deficits that comprise the Gerstmann syndrome (Frederiks, 1985; Ogden, 1985).

Finger agnosia, as initially described by Gerstmann in 1924 (Gerstmann, 1940), includes the inability to distinguish, name, or recognize the fingers not only in the patient's own hands, but also in the examiner's hand or in a drawing of a hand. The patient presents difficulties in selectively moving the fingers, both by verbal command or by imitation. The most evident errors are observed in the index, middle, and ring fingers. Usually the patient has difficulties in recognizing his or her errors and consequently does not try to correct them. Later on, Gerstmann (1940) amalgamated finger agnosia, plus right-left disorientation, agraphia and acalculia into a single syndrome.

Some authors have proposed that finger agnosia represents a mild form of autotopagnosia (e.g. Hécaen and Albert, 1978). However, it has been reported that autotopagnosia and finger agnosia can appear dissociated, and consequently represent different defects (De Renzi and Scotti, 1970). Finger agnosia is a relatively frequent defect, whereas autotopagnosia represents a relatively unusual syndrome. It has been proposed that finger agnosia might be a polymorphic phenomenon, that includes apraxic, agnosic and aphasic aspects. In consequence, different subtypes of finger agnosia can be distinguished: visual finger agnosia, finger constructional apraxia, apractic defects in finger selection, and finger aphasia (anomia) (Schilder and Stengel, 1931).

Pathogenesis of right-left disorientation is not completely understood either. It includes the inability to identify right and left in the patient's own and in the examiner's body. It would include not only linguistic but also spatial components (to use "right" and "left" to refer to the body lateral dimensions). Patients with left posterior damage present more obvious difficulties than right posterior damaged-patients (Ratcliff, 1979). Right-left disorientation implies difficulties in the application of spatial concepts in the body's lateral orientation. As in finger agnosia, rightleft disorientation is observed in cases of left posterior parietal damage, and can be included within the left angular gyrus syndrome.

The existence of the Gerstmann syndrome has been polemic and even questioned in the literature (Poeck and Orgass, 1966; Benton, 1977; Strub and Geschwind, 1983; Botez, 1985). Usually, it appears in an "incomplete" presentation, or is associated with other defects, particularly aphasia, alexia and perceptual disorders (Frederiks, 1985). 
The presence of the Gerstmann syndrome (complete or incomplete) suggests some left posterior parietal damage (left angular gyrus), and the name "angular syndrome" has been proposed to replace "Gerstmann syndrome" (Benson, 1979; Strub and Geschwind, 1983). The report of Morris et al. (1984) on the appearance of a Gerstmann syndrome with electrical stimulation of the cerebral cortex would affirm its angular localization. Recently, Mazzoni et al. (1990) described a new clear case of a "pure" Gerstmann syndrome, associated with angular gyrus traumatic damage.

Some authors have reported the presence of Gerstmann syndrome without aphasia (Strub and Geschwind, 1974; Roeltgen et al., 1983; Varney, 1984). However, the existence of a possible semantic aphasia has not been specifically explored and ruled out (Ardila et al., 1989a). According to Strub and Geschwind (1983), the localization of the Gerstmann syndrome would be angular, with the lesion extending not toward the occipital lobe (as Gerstmann proposed) but toward the supramarginal gyrus and the interior parietal gyrus. The agraphia would correspond to an apractic (and not aphasic) agraphia, and in consequence it is not necessarily associated with alexia (Benson and Cummings, 1985).

In cases of "incomplete" Gerstmann syndrome, usually agraphia is the missing sign. This may be because the topography of apractic agraphia is not exactly angular, but inferior parietal. Ardila et al. (1989a) proposed replacing agraphia for semantic aphasia as a part of the angular gyrus syndrome; or simply considering semantic aphasia as a fifth sign of the Gerstmann syndrome. Thus, Gerstmann (or angular) syndrome would include: acalculia, finger agnosia (or a more extended autotopagnosia), right-left disorientation, and semantic aphasia. Sometimes, agraphia without alexia will be observed, but agraphia would result from an inferior parietal lesion, not exactly from an angular pathology.

\section{ACALCULIA}

Henschen (1925) introduced the term "acalculia" to refer to the impairments in mathematical abilities in cases of brain damage. Berger (1926) distinguished two different types of acalculia: primary and secondary acalculia. Secondary acalculia refers to a calculation defect resulting from an associated cognitive deficit: memory, attention, language, etc. As mentioned above, Gerstmann (1940) proposed that acalculia is observed together with agraphia, disorders in right-left orientation, and finger agnosia, comprising the single brain syndrome.

Boller and Grafman $(1983,1985)$ consider that calculation abilities can be disrupted as a result of: (1) inability to appreciate the meaning of the number names; (2) visuospatial defects that interfere with the spatial arrange- ments of numbers and the mechanical aspects of mathematical operations; (3) inability to recall mathematical facts and appropriately use them; and (4) defects in mathematical thinking and in understanding underlying operations. Further could be added; (5) inability to conceptualize quantities (numerosity) and invert operations (e.g. adding-subtracting).

A general cognitive model of number processing and calculation has been proposed by McCloskey et al. (1985, 1986, 1991) and McCloskey and Caramazza (1987). A distinction is drawn between the number processing system, which comprises the mechanisms for comprehending and producing numbers, and the calculation system, which encompasses the processing components required specifically for carrying out calculations. In the case of brain pathology, eventually these components can be dissociated. Facts (e.g. the multiplication tables), rules (e.g. $\mathrm{N} \times 0=0$ ) and procedures (e.g. multiplying goes from right to left) are included as elements of the calculation system. Errors in calculation observed in braindamaged and normal subjects, can result from inappropriate fact retrieval, misuse of arithmetical rules, and procedural errors.

Ardila and Rosselli (1990) have proposed a classification of acalculias (Table I). A basic distinction between anarithmetia (primary acalculia) and acalculia resulting from other cognitive defects (secondary acalculia) is included. Secondary acalculias may result from linguistic defects (oral or written), spatial deficits and frontal-type disturbances, particularly perseveration, memory, and attentional impairments. There is, however, certain overlapping among the acalculia subtypes proposed by Ardila and Rosselli. Thus, in anarithmetia there are also some spatial deficits; spatial acalculia observed in cases of right hemisphere damage is also partially an alexic acalculia.

Anarithmetia represents the real primary acalculia. It is observed in cases of left angular gyrus damage (Grafman, 1988). These patients present a loss of numerical concepts, inability to understand quantities, defects in performing basic arithmetical operations, inability to make use of the basic syntactic rules of calculation (e.g. to carry), and very

TABLE I. Types of acalculia (from Ardila and Rosselli, 1990)
1. Anarithmetia
2. Aphasic acalculia
in Broca aphasia
in Wernicke aphasia
in conduction aphasia
3. Alexic acalculia
in pure alexia
in alexia with agraphia
4. Agraphic acalculia
5. Frontal acalculia
6. Spatial acalculia 
often, inability to read arithmetical signs. Hécaen et al. (1961) found certain overlapping between anarithmetia, alexia and agraphia for numbers. In a sample of 73 braindamaged patients with anarithmetia, they found that $62 \%$ presented aphasia, $61 \%$ constructional deficits, $54 \%$ visual field impairments, $50 \%$ generalized cognitive defects, $39 \%$ verbal alexia, and $33 \%$ oculomotor defects. The sample used by Hécaen et al. was, however, too heterogeneous, and acalculia could easily be correlated with some additional defects.

Rosselli and Ardila (1989) analyzed calculation defects in patients with left posterior parietal damage. These patients presented errors in transcoding tasks, performing successive arithmetical operations, and solving arithmetical problems. Seventy-five per cent of the patients presented errors in reading and using arithmetical signs, reading and writing numbers. They were also unable to use syntactic rules (e.g. to "carry", to "borrow"), but correctly interpreted "bigger" and "smaller" relationships (i.e. which of two numbers is bigger or smaller). They could count forwards, but $50 \%$ of the patients failed in counting backwards.

Dahmen et al. (1982) studied the calculation defects in patients with Broca's and Wernicke's aphasia. Using a factor analysis they were able to identify two different factors: numeric-symbolic and visual-spatial. The milder calculation defects found in Broca aphasia patients are derived from their linguistic alterations; while in Wernicke aphasia, defects in visual-spatial processing significantly contribute to the calculation difficulties. Luria $(1966,1973)$ also emphasized the presence of defects in spatial conceptualization underlying the acalculia observed in left parietal-damaged patients and the strong association between acalculia and semantic aphasia.

It could be proposed that in the case of primary acalculia associated with left parietal damage, global quantification ability, and probably correspondence construction, are preserved. However, the basic principles used in counting (one-to-one principle: each object in a collection is to be paired with one and only one number name; stable order principle: each name is assigned to a permanent ordinal position in the list; and cardinal principle: the final number name used in a counting sequence refers to the cardinal value of the sequence) may be impaired. In aphasic patients, however, counting can be preserved (Seron et al., 1991). Evidently, computational strategies required in arithmetical operations (adding, subtracting, multiplying and dividing) and mathematical problem-solving ability, are severely disrupted.

Calculation ability might be interpreted as a type of cognition involving, in its origins at least, some type of body knowledge (autotopagnosis), spatial concepts, and language. The association between spatial knowledge mediated through language and calculation abilities has been strongly emphasized by different authors (e.g. Luria, 1966, 1976; Ardila et al., 1989a). Luria underlines that the so-called semantic aphasia (inability to use verbally mediated spatial concepts) is always associated with acalculia.

The role of the parietal lobe in body-knowledge, and the disorders of the body scheme in cases of parietal pathology have been usually emphasized in the literature (e.g. Critchley, 1953; Botez, 1985). Parietal damage has been associated with asomatognosia in general, and hemiasomatognosia, alloesthesia, finger agnosia, autotopagnosia, asymbolia for pain, apraxia, and the so-called Verger-Dejerine syndrome (Hécaen and Albert, 1978).

Asymmetry in cerebral organization of cognition represents the most outstanding characteristic of the human brain. LeDoux $(1982,1984)$ proposed that the primary functional distinction between human hemispheres involves the differential representation of linguistic and spatial mechanisms: while the right posterior parietal lobe is involved in spatial processing, the left posterior parietal lobe is involved in linguistic processing. Spatial mechanisms are represented in both the right and the left parietal lobe in non-human primates, but in humans language is represented in a region (posterior parietal lobe) of the left hemisphere which, in the right hemisphere, is involved in spatial functions, and was involved in spatial functions in both hemispheres in human ancestors (Lynch, 1980). In consequence, the evolution of language involved adaptations in the neural substrate of spatial behavior (LeDoux, 1984). Boles (1991), presenting different tasks (recognition of words, products, locations, dichotic digits, etc.) and using a factor analysis, was able to identify different lateralized parietal functions: lexical functions (e.g. word numbers) were associated with left hemisphere, whereas spatial functions (e.g. locations of dots) were correlated with right hemisphere activity.

\section{CONCLUSIONS}

Counting, finger gnosis and even lateral spatial knowledge may have a common historical origin. Seemingly, calculation abilities were derived from finger sequencing. Number representation and arithmetical operations are observed only in the last 5000-6000 years. Currently, calculation abilities are rapidly evolving due to the introduction of modern technology.

Right-left discrimination (as well as the use of other spatial concepts) most likely were present in prehistorical humans. Requirements of spatial abilities may have been very high, even higher than in contemporary humans (Hours, 1982; Ardila and Ostrosky, 1984). Rightleft discrimination and finger gnosis are strongly interdependent and can be interpreted as components of the 
autotopagnosia syndrome. It seems, in consequence, that a rationale exists for finding a common brain activity for finger gnosis, calculation, and right-left discrimination (and in general, spatial knowledge mediated by language).

\section{Acknowledgements}

The author wishes to express his sincere gratitude to Drs Jordan Grafman, Francisco Queixalos and Diego Rosselli for their very valuable suggestions when preparing this paper.

\section{REFERENCES}

Antell SE and Keating D (1983) Perception of numerical invariance by neonates. Child Development, 54, 695-701.

Ardila A and Ostrosky F (1984). Some final remarks. In: The Right Hemisphere: Neurology and Neuropsychology (Eds A Ardila and F Ostrosky-Solis), pp. 265-273. Gordon and Breach, London.

Ardila A and Rosselli M (1986) La Vejez: Neuropsicologia del Fenómeno del Envajecimiento [Neuropsychology of Aging]. Prensa Creativa, Medellin, Colombia.

Ardila A and Rosselli M (1990) Acalculias. Behavioural Neurology, 3, 39-48.

Ardila A and Rosselli M (1992) Neuropsicologia Clinica [Clinical Neuropsychology]. Prensa Creativa, Medellin, Colombia.

Ardila A, Lopez MV and Solano E (1989a) Semantic aphasia reconsidered. In: Brain Organization of Language and Cognitive Processes (Eds A Ardila and F Ostrosky-Solis), pp. 177193. Plenum, New York.

Ardila A, Rosselli M and Rosas P (1989b) Neuropsychological assessment in illiterates: Visuospatial and memory abilities. Brain and Cognition, 11, 146-166.

Benson DF (1979) Aphasia Alexia and Agraphia. Churchill Livingstone, New York.

Benson DF and Cummings JL (1985) Agraphia. In: Handbook of Clinical Neurology: Clinical Neuropsychology, Vol. 45 (Ed. J.A.M. Frederiks), pp. 457-473. Elsevier, Amsterdam.

Benton A (1977) Reflection on the Gerstmann syndrome. Brain and Language, 4, 45-62.

Berger H (1926) Uber Rechenstorunger bei Herderkraunkunger des Grosshirns. Archives Psychiatrie und Nervenkr, 78, 236-263.

Boles DB (1991) Factor analysis and the cerebral hemispheres: pilot study and parietal functions. Neuropsychologia, 29, 59-91.

Boller F and Grafman J (1983) Acalculia: historical development and current significance. Brain and Cognition, 2, 205-223.

Boller F and Grafman J (1985) Acalculias. In: Handbook of Clinica Neurology: Clinical Neuropsychology, Vol. 45 (Ed. JAM Frederiks), pp. 473-482. Elsevier, Amsterdam.

Botez M (1985) Parietal lobe syndromes. In: Handbook of Clinica Neurology: Clinical Neuropsychology, Vol. 45 (Ed. JAM Frederiks), pp. 63-86. Elsevier, Amsterdam.

Cauty A. (1984) Taxonomie, syntaxe et economie des numerations parlèes. Amerindia, 9, 111-146.

Childe VG (1936) Man Makes Himself. Pitman, London.

Critchley M (1953) The Parietal Lobe. Edward Arnold, London.

Dahmen W, Hartje W, Bussing A and Sturm W (1982) Disorders in calculation in aphasic patients - spatial and verbal components. Neuropsychologia, 20, 145-153.

Davis H and Pérusse R (1988) Numerical competence in animals. Behavioral and Brain Sciences, 11, 561-615.
Davis H, Albert M and Barron RW (1985) Detection of number or numerousness by human infants. Science, 228, 1222.

Dennis M (1976) Dissociated naming and locating of body parts after left anterior temporal lobe resection: an experimental case study. Brain and Language, 3, 147-163.

De Renzi E (1982) Disorders of Space Exploration and Cognition. Wiley, New York.

De Renzi E and Scotti G (1970) Autotopagnosia: Fiction or reality? Archives of Neurology, 23, 221-227.

Frederiks JAM (1985) Disorders of the body schema. In: Handbook of Clinical Neurology: Clinical Neuropsychology, Vol. 45 (Ed. JAM Fredriks), pp. 373-394. Elsevier, Amsterdam.

Gelman R and Meck E (1983) Preschoolers' counting: principles before skill. Cognition, 13, 343-359.

Gerstmann J (1940) The syndrome of finger agnosia, disorientation for right and left, agraphia and acalculia. Archives of Neurology, Neurosurgery and Psychiatry, 44, 398-408.

Goodwin DM (1989) A Dictionary of Neuropsychology. Springer-Verlag, New York.

Grafman J (1988) Acalculia. In: Handbook of Neuropsychology, Vol. 1 (Eds F Boller, J Grafman, G Rizzolatti and H Goodglass), pp. 415-432. Elsevier, Amsterdam.

Grafman J and Boller F (1987) Cross-cultural approaches to the study of calculation processes. In: Mathematical Disabilities: A Cognitive Neuropsychological Perspective (Eds G Deloche and X Seron), pp. 257-272. Lawrence Erlbaum Associates, Hillsdale, NJ.

Grafman J, Passafiume D, Faglioni P and Boller F (1982) Calculation disturbances in adults with focal hemispheric damage. Cortex, 18, 37-49.

Grafman J, Kampen D, Rosenberg J, Salazar AM and Boller F (1989) The progressive breakdown of number processing and calculation ability: A case study. Cortex, 25, 121-133.

Greenberg JH (1978) Universals of Human Language, Vols 1-4. Stanford University Press, Stanford.

Groen GJ and Resnick LB (1977) Can preschool children invent addition algorithms? Journal of Educational Psychology, 69, 645-652.

Hagége C (1982) La Structure des Langues. Presses Universitaires de France, Paris.

Harris M (1983) Cultural Anthropology. Harper \& Row, New York.

Hécaen H and Albert ML (1978) Human Neuropsychology. Wiley, New York.

Hécaen H, Angelergues T and Houiller S (1961) Les varietes cliniques des acalculies au cours de lesions retrorolandiques. Revue de Neurologie, 105, 85-103.

Henschen SE (1925) Clinical and anatomical contributions on brain pathology. Archives of Neurology and Psychiatry, 13, 226-249.

Hier DB, Mogil SI, Rubin NP and Komros GR (1980) Semantic aphasia: A neglected entity. Brain and Language, 10, 120-131.

Hitch G, Cundick J, Haughey M, Pugh R and Wright H (1987) Aspects of counting in children's arithmetics. In: Cognitive Processes in Mathematics (Eds JA Sloboda and D Rogers), pp. 26-41. Clarendon Press, Oxford.

Hours F (1982) Les Civilisations du Paléolithique. Presses Universitaires de la France, Paris.

Klein A and Starkey PS (1987) The origins and development of numerical cognition: A comparative analysis. In: Cognitive Processes in Mathematics (Eds JA Sloboda and D Rogers), pp. 1-25. Clarendon Press, Oxford.

Kolb B and Whishaw IQ (1990) Fundamentals of Human 
Neuropsychology, 3rd edn. Freeman and Company, New York.

Langer J (1986) The Origins of Logic: One to Two Years. Academic Press, New York.

LeDoux JE (1982) Neuroevolutionary mechanisms of cerebral asymmetry in man. Brain, Behavior and Evolution, 20, 197-213.

LeDoux JE (1984) Cognitive evolution: clues from brain asymmetry. In: The Right Hemisphere: Neurology and Neuropsychology (Eds A Ardila and Feggy Ostrosky-Solis), pp. 51-60. Gordon and Breach, London.

León-Portilla M (1986) Tiempo y Realidad en el Pensamiento Maya [Time and Reality in Maya Thinking]. Universidad Nacional Autonoma de Mexico, Mexico.

Levin H and Spiers PA (1985) Acalculia. In: Clinical Neuropsychology 2nd edn (Eds KM Heilman and E Valenstein), pp. 97 114. Oxford University Press, New York.

Levy-Bruhl L (1910, 1947) Las Funciones Mentales en las Sociedades Inferiores [Mental functions in Lower Societies]. Lautaro, Buenos Aires.

Luria AR (1966) Higher Cortical Functions in Man. Basic Books, New York.

Luria AR (1973) The Working Brain. Basic Books, New York.

Luria AR (1976) Basic Problems in Neurolinguistics. Mouton, New York.

Lynch JC (1980) The functional organization of posterior parietal association cortex. Behavioral and Brain Sciences, 3, 485-534.

Mazzoni M, Pardossi L, Cantini R, Giornetti V and Arena R (1990) Gerstmann syndrome: a case report. Cortex, 25, 459-468.

McCloskey M and Caramazza A (1987) Cognitive mechanisms in normal and impaired number processing. In: Mathematical Disabilities: A Cognitive Neuropsychological Perspective (Eds G Deloche and X Seron), pp. 201-220. Lawrence Erlbaum Associates, Hillsdale, NJ.

McCloskey M, Caramazza A and Basili A (1985) Cognitive processes in number processing and calculation: Evidence from dyscalculia. Brain and Cognition, 4, 313-330.

McCloskey M, Sokol SM and Goodman RA (1986) Cognitive processes in verbal number processing: inference from the performance of brain-damaged subjects. Journal of Experimental Psychology: General, 115, 313-330.

McCloskey M, Aliminosa D and Sokol SM (1991) Facts, rules, and procedures in normal calculation: evidence from multiple single-patient studies of impaired arithmetic fact retrieval. Brain and Cognition, 17, 154-203.

Morris HH, Luders H, Lesser RP, Dinner DS and Hahn J (1984) Transient neuropsychological abnormalities (including Gerstmann's syndrome) during cortical stimulation. Neurology, 34, 877-883.

Ogden JI (1985) Autotopagnosia. Brain, 108, 1009-1022.

Parker ST and Gibson KH (1979) A developmental model for the evolution of language and intelligence in early hominids. Behavioral and Brain Sciences, 2, 367-408.
Pick A (1908) Ueber Storungen der Orienterung an eigenen Korper. Arbeiten aus den deutschen psychiatrischen Universitatsklinik in Prag. Karger, Prague.

Poeck K and Orgass B (1966) Gerstmann's syndrome and aphasia. Cortex, 2, 421-437.

Poncet M, Pelissier JF, Sebahoun M and Nasser CJ (1971) A propos d'un case d'autotopoagnosie secondaire a un lésion pariéto-occipitale de l'hemisphere majeur. Encéphale, 60, $1-14$.

Posner JK (1982) The development of mathematical knowledge in two West African societies. Child Development, 53, 200-208.

Premack D (1976) Intelligence in Ape and Man. Erlbaum, Hillsdale, NJ.

Queixalos F (1985) L'orientation spatiale dans la grammaire Sikuani. Journal de la Société des Américanistes, 71, 115-128.

Queixalos F (1989) Numeración tradicional Sikuani [Traditional Sikuani numbering]. Glotta, 3, 28-31.

Ratcliff G (1979) Spatial thought, mental rotation and the right hemisphere. Neuropsychologia, 13, 191-206.

Roeltgen D, Sevush S and Heilman KM (1983) Pure Gerstmann's syndrome from a focal lesion. Archives of Neurology, 40, $46-47$.

Rosin RT (1972) Gold medallions: the arithmetic calculations of an illiterate. Council on Anthropology and Education Newsletter, 4, 1-9.

Rosselli M and Ardila A (1989) Calculation deficits in patients with right and left hemisphere damage. Neuropsychologia, 27, 607-618.

Schilder P and Stengel E (1931) Asymbolia for pain. Archives of Neurology and Psychiatry, 25, 598-600.

Semenza C (1988) Impairment in localization of body parts following brain damage. Cortex, 24, 443-449.

Seron X, Deloche G, Ferrand I, Cornet JA, Frederix M and Hirsbrunner T (1991) Dot counting by brain-damaged subjects. Brain and Cognition, 17, 116-137.

Sirigu A, Grafman J, Bressler K and Sunderland T (1991) Multiple representations contribute to body knowledgement. Evidence from a case of autotopagnosia. Brain, 114, 629-642.

Strub RL and Geschwind N (1974) Gerstmann syndrome without aphasia. Cortex, 10, 378-387.

Strub R and Geschwind N (1983) Localization in Gerstmann syndrome. In: Localization in Neuropsychology (Ed. A. Kertesz), pp. 295-322. Academic Press, New York.

Swadesh M (1967) El Lenguage y La Vida Humana [Language and Human Life]. Fondo de Cultura Económica, Mexico.

Turner R (1984) The Great Cultural Tradition. The Foundation of Civilization. McGraw-Hill, New York.

Varney NR (1984) Gerstmann syndrome without aphasia: A longitudinal study. Cortex, 10, 378-387.

Warrington EK (1982) The fractionation of arithmetical skills: A single case study. Quarterly Journal of Experimental Psychology, 34A, 31-55. 


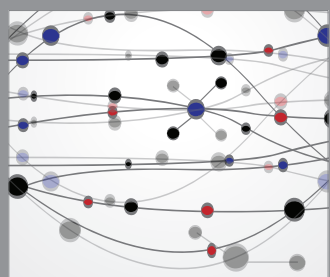

The Scientific World Journal
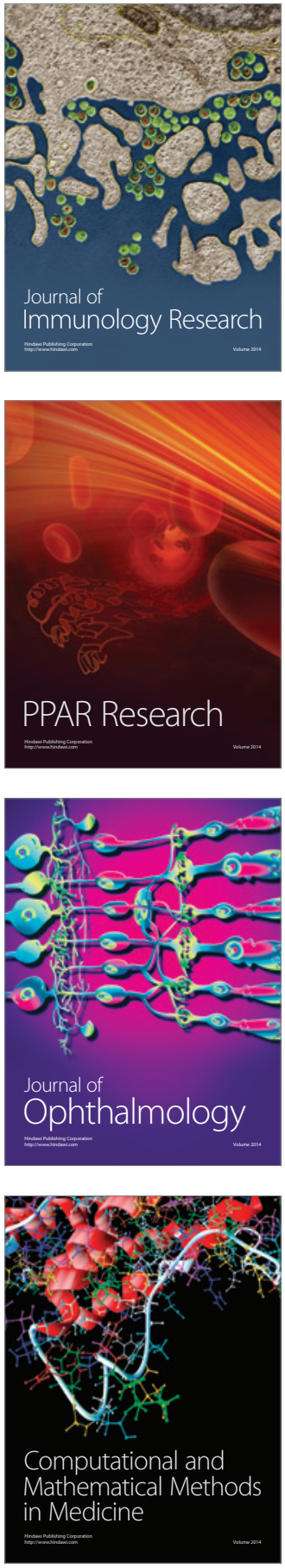

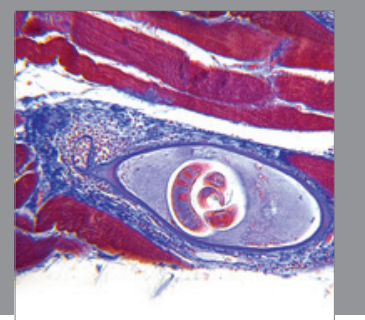

Gastroenterology

Research and Practice
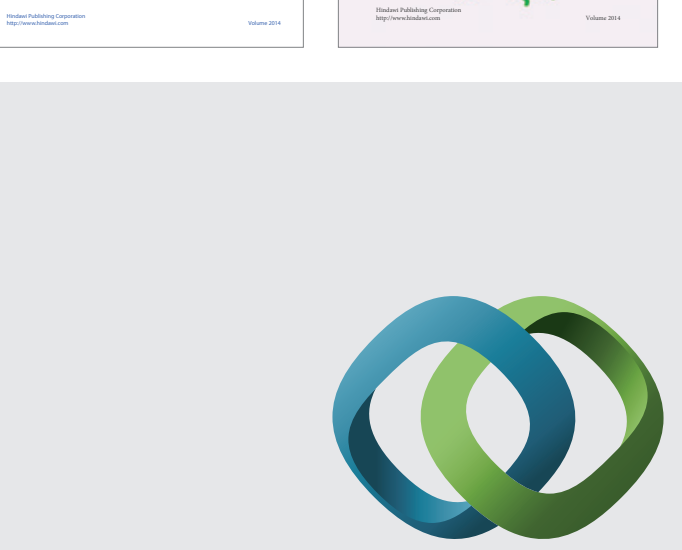

\section{Hindawi}

Submit your manuscripts at

http://www.hindawi.com
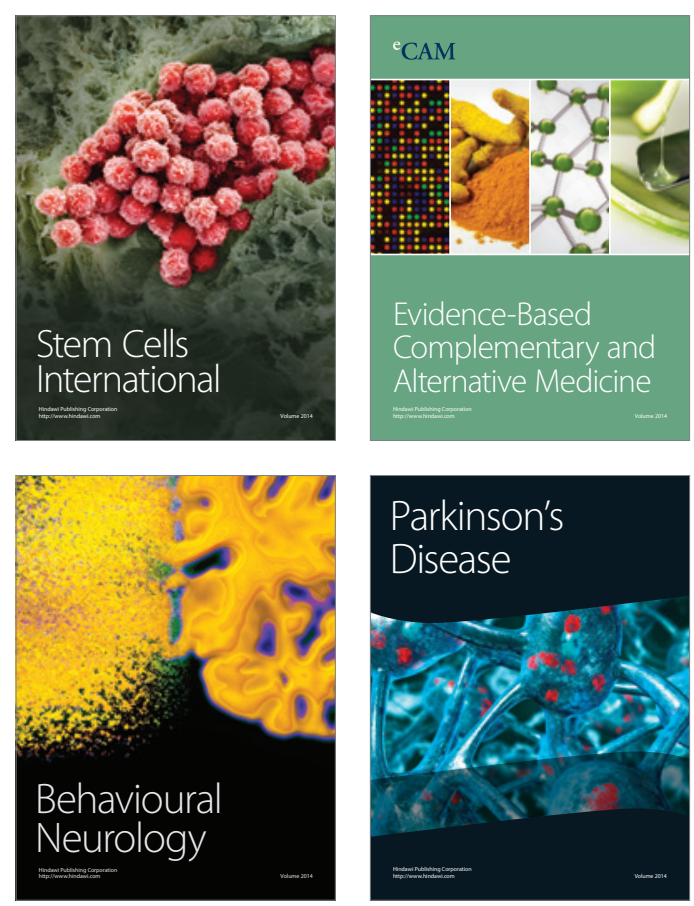

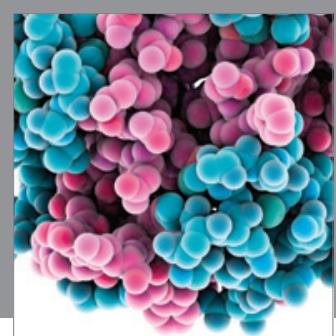

Journal of
Diabetes Research

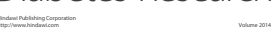

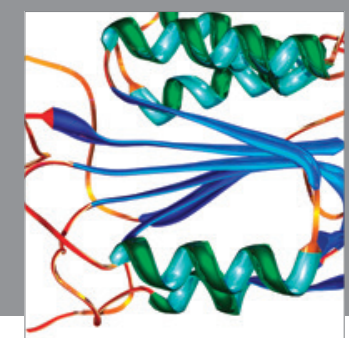

Disease Markers
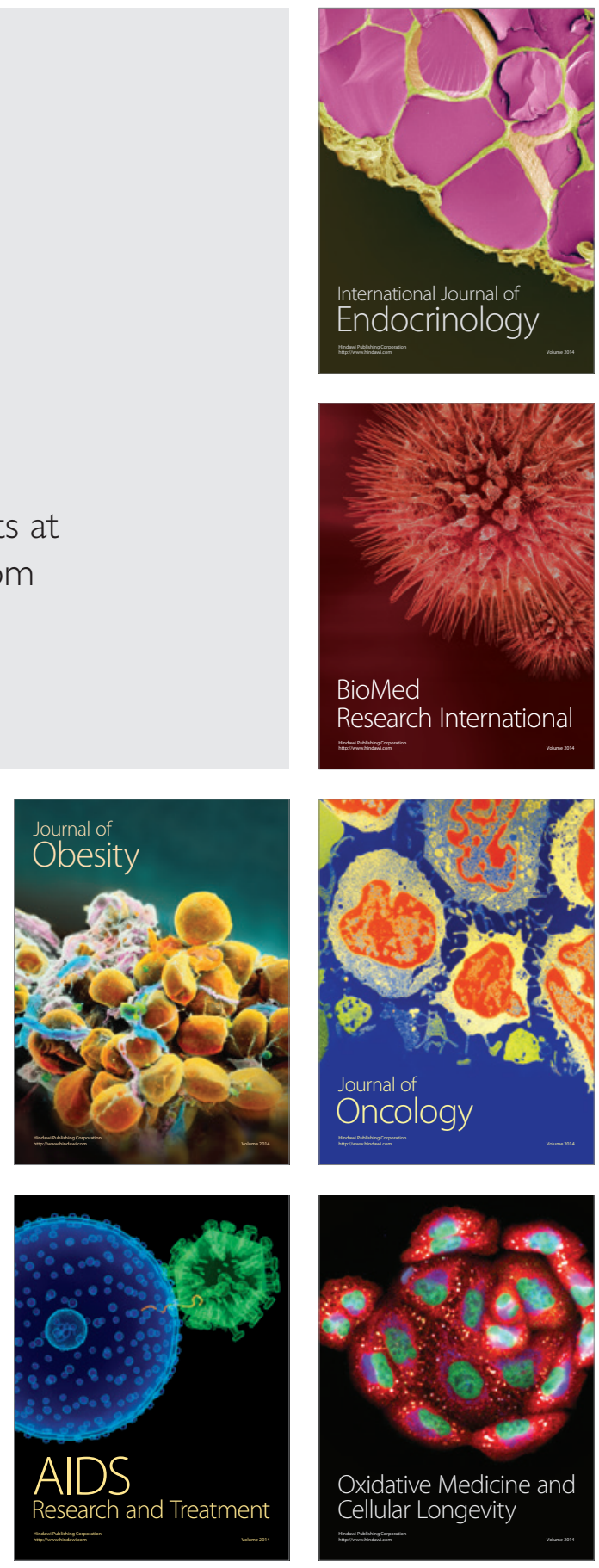